\title{
The effect of cochlear implantation on autonomy, participation and work in postlingually deafened adults: a scoping review
}

\author{
Hugo G. B. Nijmeijer ${ }^{1,2}$ (D) Noud M. Keijsers ${ }^{1} \cdot$ Wendy J. Huinck ${ }^{1,2} \cdot$ Emmanuel A. M. Mylanus $^{1,2}$
}

Received: 14 September 2020 / Accepted: 10 November 2020 / Published online: 27 November 2020

(c) The Author(s) 2020

\begin{abstract}
Purpose This scoping review examines the available evidence on the effect of unilateral cochlear implantation (CI) in adults with postlingual bilateral hearing loss on societal-related outcomes in terms of work, autonomy and participation.

Methods Five databases were searched (Pubmed, Web of Science, Embase, PsycINFO and Cochrane Library). Publications were screened in three steps on inclusion criteria. Of the 4230 screened publications, 110 met the inclusion criteria and were assessed for data extraction regarding outcomes "work", "autonomy", "participation". Study characteristics and key findings are presented and narratively described.

Results Twenty-seven publications were included and categorized into retrospective $(n=3)$, cross-sectional $(n=18)$ or prospective $(n=6)$ study designs. Measurement or identification of number of outcomes (no) were related to work $($ no $=20)$, participation $($ no $=9)$ and autonomy or independency $($ no $=10)$. Most studies indicated benefits of CI on these outcomes. However, some studies did not or indicated additional barriers for benefits. Eleven publications primarily aimed to study one or more of our primary outcomes.

Conclusion In this literature search, scientific databases are reviewed. The results indicate that there is a relatively small body of evidence regarding the effect of CI on the outcomes "work", "autonomy" and "participation". Even though there are some limitations of the current study including some overlap in outcome definitions, most included studies indicate a beneficial effect of CI on work, autonomy and participation. The lack of consensus in definitions and the small body of evidence indicates a need for additional prospective studies investigating the societal outcomes of CI in postlingually deafened adults.
\end{abstract}

Keywords Cochlear implant $\cdot$ Hearing loss $\cdot$ Work $\cdot$ Autonomy $\cdot$ Participation

\section{Introduction}

Hearing loss in adults gives rise to limitation in communication, with evident negative consequences in daily life [1]. In 2017, the World Health Organization (WHO) presented a report on the prevention of hearing loss that states that adults

Electronic supplementary material The online version of this article (https://doi.org/10.1007/s00405-020-06490-x) contains supplementary material, which is available to authorized users.

Hugo G. B. Nijmeijer

hugo.nijmeijer@radboudumc.nl

1 Department of Otorhinolaryngology and Head and Neck Surgery, Radboud university medical center, P.O. Box 9101, Nijmegen 6500 HB, The Netherlands

2 Donders Institute for Brain, Cognition and Behavior, Radboud university medical center, P.O. Box 9101, Nijmegen 6500 HB, The Netherlands with unaddressed hearing loss have higher unemployment rates than the rest of the population. Daily limitations in hearing and understanding speech lead to fatigue and more recovery time from work $[2,3]$. Furthermore, older adults with hearing loss face significant physical and social challenges, their hearing disability contributes to social isolation and loss of autonomy with associated anxiety, depression, cognitive deficits and dementia $[4,5]$.

There are multiple causes of hearing loss and-depending on the type and cause of hearing loss-it is often progressive in nature [6]. The WHO defines hearing loss by ISO 4PTAdB hearing loss as follows: slight $/$ mild $=26-40 \mathrm{~dB}$; moderate $=41-60 \mathrm{~dB}$; severe $=61-81 \mathrm{~dB}$; profound $>81 \mathrm{~dB}$ [7]. At the levels of severe and profound hearing loss, the use of hearing aids might no longer result in hearing benefits. Following natural progression, these patients would often rely on sign language and lipreading. 
However, since a couple of decades, rehabilitation of severe to profoundly deaf individuals is possible with cochlear implants (CIs). CI has demonstrated to improve audition, speech perception and health-related quality of life (HRQoL). Unilateral cochlear implantation has proven to be a cost-effective intervention for rehabilitation of patients with profound bilateral sensorineural hearing loss [8]. Till now, alternatives to $\mathrm{CI}$ for rehabilitation of these profound cases of hearing loss is limited to educational programs for the deaf [6].

CI efficacy and effectiveness have been demonstrated in clinical studies, often conducted in controlled laboratory setups (anechoic soundproof booths). This has often been studied in clinical settings using psycho-acoustic measures like speech perception in noise and sound localization tests. In addition, changes in HRQoL have frequently been evaluated using generic [for example the Health Utility Index Mark 111 (HUI3)] and disease-specific [for example Nijmegen Cochlear Implant Questionnaire (NCIQ)] health-related quality of life questionnaires.

However, besides health-related quality of life, audition and communication, there are other interrelated, important aspects for an individual who participates in a complex society. The experienced benefit of the patient in society may differ from their clinical audiologic improvement. Measuring these societal outcomes reveals information about the value of $\mathrm{CI}$ for the individual and society as a whole. Proper understanding of the societal benefit of CI may help justify its budgetary burden, which is bound to increase as a result of demographic changes. The Dutch National Institute for Public Health and the Environment (RIVM) projects a scenario of $48 \%$ increase in absolute number of patients with hearing disorders between 2015 and 2040 [9].

In scientific and grey literature, these societal-related benefits of CI have often been addressed theoretically, but have not always been studied in a systematic manner. We are interested in the current body of evidence regarding societal-related outcomes which we further specified as work; autonomy; participation; quality of life (QoL), cognition and communication. Conducting a scoping review is suitable to provide an overview of the existing evidence and report on the types of evidence that investigates the effect of CI on these societal-related outcomes [10].

The aim of this scoping review is to examine the extent of available research regarding the effect of unilateral cochlear implantation in adults with postlingual bilateral hearing loss on societal-related outcomes in terms of work, autonomy, and participation. This is of importance to guide future research and/or inform policy makers about cochlear implantation and for the counseling of individual patients.

\section{Methods}

This scoping review was conducted based on the methodological framework described in the Joanna Briggs Institute Reviewers manual [10]. Reporting was based on the Preferred Reporting Items for Systematic reviews and MetaAnalyses extension for Scoping Reviews (PRISMA-ScR) checklist [11].

\section{Eligibility criteria}

In the search strategy of this study, the following search criteria were used.

\section{Population}

Adults ( $\geq 18$ years of age) with severe and profound hearing loss according to the WHO classification (severe: $61-80 \mathrm{~dB}$ HL, profound: $>81 \mathrm{~dB}$ HL) or complete deafness were included. We excluded studies in which participants were only patients with specific underlying disorders or co-morbidities, such as blindness or Parkinson's disease. Publications were excluded if they exclusively investigated animals, children, prelingually deaf adults, single-sided deafness (SSD) patients or bilaterally implanted patients.

\section{Intervention and comparator}

All publications investigating the effect of cochlear implants, bimodal and electric acoustic stimulation (EAS) fitting were included. Studies without a comparison between patients with and patients without unilateral CI or exclusively studying bilateral implantation were excluded. Studies that investigated interventions post CI surgery to improve CI outcomes were excluded. In addition, studies exclusively investigating surgical procedures, imaging, CI device specifications, fitting procedures and (patho)physiology were excluded.

\section{Outcomes}

Autonomy is defined as the ability of living the way you want without being dependent on other people, independence. Participation is defined as the ability to participate or participating in (social) events and activities that an individual wants to attend. Work is described as being employed and how this employment is being experienced, as well as being engaged in activities that are perceived either by the $\mathrm{CI}$ recipient or by co-workers as work. In the present review, the outcomes are considered as relevant if the authors of the particular study defined and measured this outcome as such. In case of qualitative studies, the results should be thematically coded in terms of these outcomes. In addition, we also 
searched for outcomes related to cognition, QoL and communication because these outcomes were considered related to our primary outcomes of interest. Cognition is not further specified; however we included memory separately in the search strategy. (Health-related) Quality of life is also included. Communication is defined as observed or selfperceived, subjective changes in communication as a result of CI. Studies that did not measure or describe one of the above outcomes were excluded. Clinical audiometric tests were excluded as those may not always correlate perfectly with perceived benefits by the patient [12].

All publications investigating the effects of unilateral CI in severe to profound postlingually deaf adults on participation, work, autonomy, QoL, communication or cognition were assessed. Also publications that focused on different primary outcome measures, but did present relevant data on the outcomes work, autonomy and participation, were assessed. Relevant reviews which did not generate new data, for instance through a meta-analysis, as well as relevant protocols of ongoing studies were kept separately. We did not put constraints on publication year. Studies written in any language other than English or Dutch were excluded.

\section{Information sources and search}

Five scientific databases (Pubmed, Web of Science, Embase, PsycINFO and Cochrane Library) were searched. A search strategy was developed and finalized by consulting a librarian from the Radboud University's medical library. The used search strategies are shown in Online Appendix 1. Duplicates were removed by using Endnote citation software. Included publications were categorized based on the investigated outcome.

\section{Study selection process}

Literature screening was performed in three steps. Two screening phases were based on title and abstract and one comprised full text screening. All screening rounds were performed by two researchers (HN and NK). In the first screening round, the publications were divided over the two researchers, because of feasibility and the breadth of the initial search. This screening round was conducted with most caution, meaning that only publications that did not meet inclusion criteria were excluded. In the second screening round, all remaining publications were exported to the literature screening software Rayyan [13], and each article was independently screened by both researchers for inclusion based on title and abstract. Conflicts were discussed till consensus was reached. The third and final screening round was also performed in Rayyan. All remaining publications were screened on full text by the two main researchers independently. As before, conflicts were discussed and solved until consensus was reached. In addition, all included publications were labeled for summarizing characteristics and data extraction.

Since this review focusses on participation, work and autonomy, no data extraction was conducted on studies solely investigating QoL, communication and cognition. The most important recent systematic reviews regarding QoL, cognition and communication are briefly described in this review.

The first search was conducted on 4-6-2019. An update search on the outcome measures work, participation and autonomy was conducted on 15-4-2020. The retrieved publications of the updated search were independently screened in two phases, title/abstract screening and full text screening, by both researchers. When there was conflict regarding inclusion, the researchers discussed until consensus was reached.

\section{Data extraction process and synthesis}

After screening, all included publications measuring or identifying participation, work or autonomy were used for data extraction. Before data extraction, a data extraction form was created. The form was tested on three publications by both researchers. The results of this test were then compared and discussed. Small adjustments were made to the data extraction form accordingly. Once all researchers agreed on the data extraction form, it was used for data extraction of all included studies. This was performed by dividing the studies over the two researchers. After completion, the researchers checked each other's work and conflicts were discussed until consensus was reached. During data extraction, the researchers maintained the used data as close as possible to the official text of the article, to ensure that the original author's nuance in claims remained intact. Because study design was not often stated explicitly, we categorized them according to retrospective, cross-sectional and prospective studies. The categories were defined according to when the study started, how often they measured outcomes and for what initial purpose. Retrospective: one or multiple measurements before the start of the described study or the data was initially used for another purpose/research. Cross-sectional: one measurement point in time after start of study for current study goals. Prospective: multiple prospective measurements at multiple time points after the start of the study and data is used for current study goals. The used data extraction form is shown in Online Appendix 2. Results of this data extraction are presented in a summary table and described narratively. 


\section{Results}

The search strategy used in Pubmed is shown in Online Appendix 1. This search method is adapted for use in Web of Science, Embase, PsycINFO and Cochrane Library. Initially, a total of 4230 unique publications were found. Due to the broad search strategy, this included a lot of studies unfit for the present study. After the first screening round based on title and abstract, 876 publications remained. Following the second screening round, 691 additional publications were excluded. The main reasons for exclusion in this phase were based on outcome (no $=338)$, intervention $($ no $=167)$, wrong publication type $(n o=138)$ or population $(n o=125)$. Finally, the remaining 185 publications were included in the full text screening, after which 75 publications were excluded. In the full text screening, the three main exclusion reasons were a wrong comparison $($ no $=25)$, no full (English) text being available $($ no $=22)$, literature reviews $($ no $=13)$, wrong publication type $($ no $=10)$ or incorrect population $($ no $=16)$.

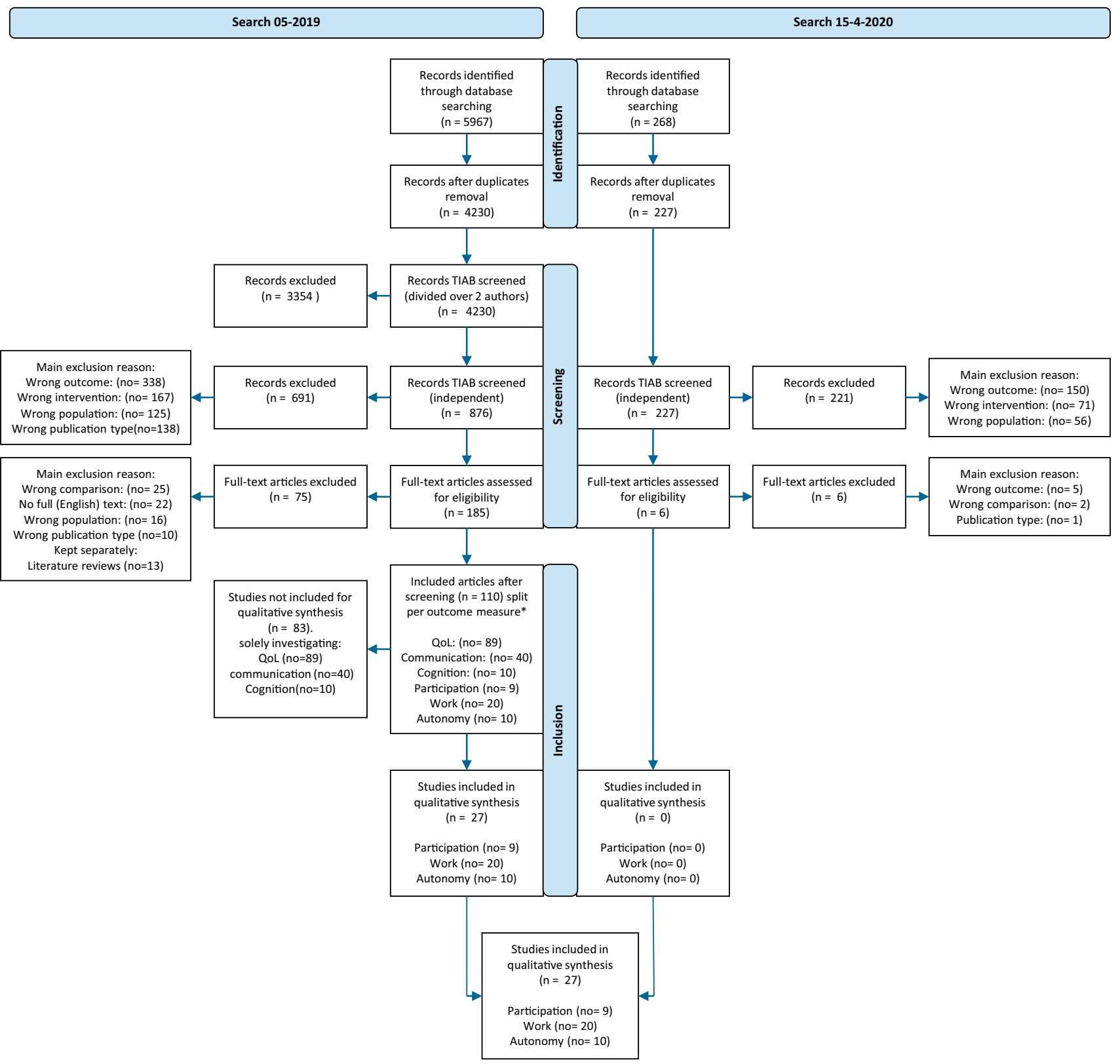

Fig. 1 Flowchart of the search strategy. Most frequent exclusion criteria are mentioned. The number of studies is indicated by ' $n$ '. Number of outcome measures investigated in the studies and if multiple exclu- sion reasons are applicable are indicated by 'no'. The total number of 'no' can be higher than ' $n$ ' 
The update search on 15-4-2020 yielded 227 publications after removing duplicates. After title and abstract screening, six publications remained for full text screening. None of the publications eventually met our inclusion criteria. The flowchart is shown in Fig. 1. Some studies investigated multiple outcomes, hence the total number of included studies is lower than the sum of total number of included studies per outcome measure. For clarification, number of studies will be indicated with " $n$ ", whereas number of outcome measures or exclusion reasons will be indicated with "no".

Twenty-seven publications reporting on participation, work or autonomy were included for the data extraction in which the outcomes of interest were measured or identified for a total of 39 times. Of these 39 outcomes, 9 included measurements about participation, 10 about autonomy and 20 about work. Unlike a systematic review, studies of various study designs can be included in a scoping review. In terms of study design, no randomized controlled clinical trials were found with the used search strategy and selection criteria. Three of the included studies were retrospective studies, 18 were cross-sectional studies, and 6 were prospective studies. The type of data investigated was categorized as qualitative in 9 studies, quantitative in 17 studies and 1 study used a mixed method approach. As there were no restrictions regarding publication date, we included 5 publications with a publication date before the year 2000, 10 studies between 2000 and 2010 and 12 studies after 2010 . Although no restrictions were used for continent or country of the studies, all included studies were published in Europe, North America or Australia. The study characteristics are presented in Table 1.

The key findings of the included studies are shown in Table 2. The entire completed data extraction form is shown in Online Appendix 2.

\section{Work}

We found 20 studies in which the effect of CI on work was measured or identified. Of these studies, there were 16 crosssectional studies (10 quantitative data, 5 qualitative data and 1 mixed methods), 2 prospective (quantitative) studies and 2 retrospective (1 quantitative and 1 qualitative) studies. Only eight studies investigated work or employment as a primary objective. The other 11 studies were either for developing a methodological tool, a secondary objective or they reported on a subscale or item of a questionnaire. Overall, most studies indicate some improvement in working performance, employment status or income after cochlear implantation. However, some studies did not observe a clear difference. The prospective quantitative study by Mo et al. assessed 27 postlingually deafened CI candidates. In this study, data were obtained pre surgery, and 12 and 15 months after surgery [14]. They showed an improvement in HRQoL
Table 1 Study characteristics: number of included publications per societal outcome measure, type of study, year of publication and continent

\begin{tabular}{|c|c|}
\hline & $\begin{array}{l}\text { Number of each measured outcome } \\
(\text { total no }=39)\end{array}$ \\
\hline \multicolumn{2}{|l|}{ Included outcome measure } \\
\hline Participation & 9 \\
\hline Autonomy & 10 \\
\hline \multirow[t]{2}{*}{ Work } & 20 \\
\hline & Number of included studies $(n=27)$ \\
\hline \multicolumn{2}{|l|}{ Type of study } \\
\hline \multicolumn{2}{|l|}{ Observational } \\
\hline Retrospective & 3 \\
\hline Cross-sectional & 18 \\
\hline Prospective & 6 \\
\hline Interventional (RCT) & 0 \\
\hline \multicolumn{2}{|l|}{ Type of data } \\
\hline Quantitative & 17 \\
\hline Qualitative & 9 \\
\hline Mixed methods & 1 \\
\hline \multicolumn{2}{|l|}{ Year of publication } \\
\hline Before 2000 & 5 \\
\hline 2000-2010 & 10 \\
\hline 2010-2020 & 12 \\
\hline \multicolumn{2}{|l|}{ Continent } \\
\hline Europe & 16 \\
\hline North America & 6 \\
\hline Australia & 5 \\
\hline
\end{tabular}

on the Patient Quality of Life Form (PQLF) [14]. However, regarding the PQLF subscale "work", there were no significant differences reported. Even though 18 participants improved, 5 were unchanged and 4 scored worse after surgery on the 'work' subscale [14]. Chapman et al. 2017 conducted a cross-sectional study, which was part of the Danish national survey, and compared CI recipients $(n=254)$ with hearing-impaired individuals without a CI $(n=574)$ [15]. Regarding the domain "challenges at work" with hearing people, they showed that people without a CI were statistical significant more likely to report cultural differences as a challenge. In the other challenges at work domains, there were no differences between the $\mathrm{CI}$ and no $\mathrm{CI}$ group on communication cooperation, isolation, social issues, other and no problems. Hogan 1997 applied a mixed method design in which they interviewed $18 \mathrm{CI}$ recipients and provided a 14-item questionnaire regarding socioeconomic status to 129 CI users, 78 patients with severe hearing loss and 33 deafened adults [16]. Implantees had a CI for an average of 7 years. According to this study, $91 \%$ of the implantees reported 'no change' pre- and post-implant. In addition, they identified that the group of implantees reported no higher incomes compared to their peers without CI [16]. 


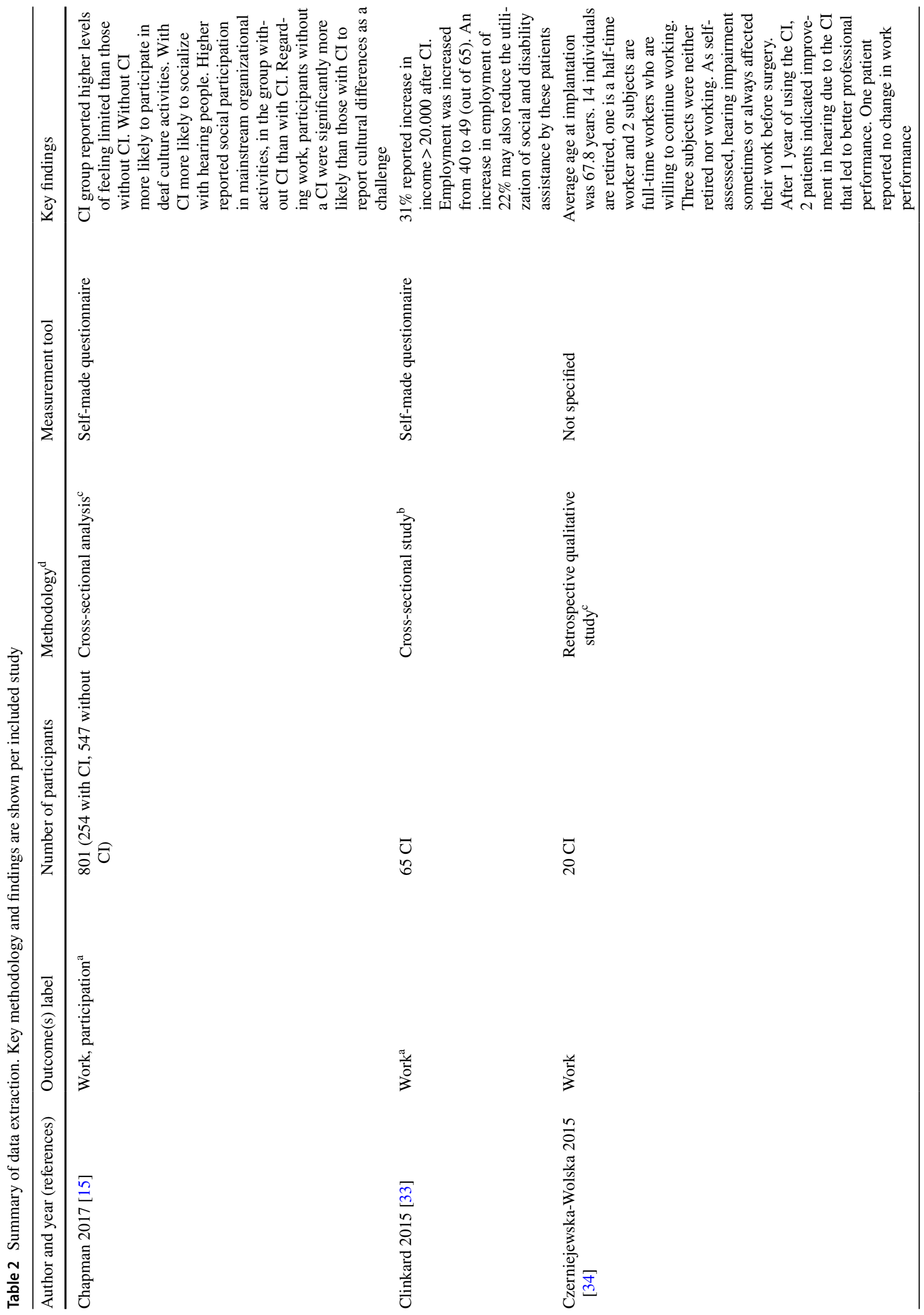




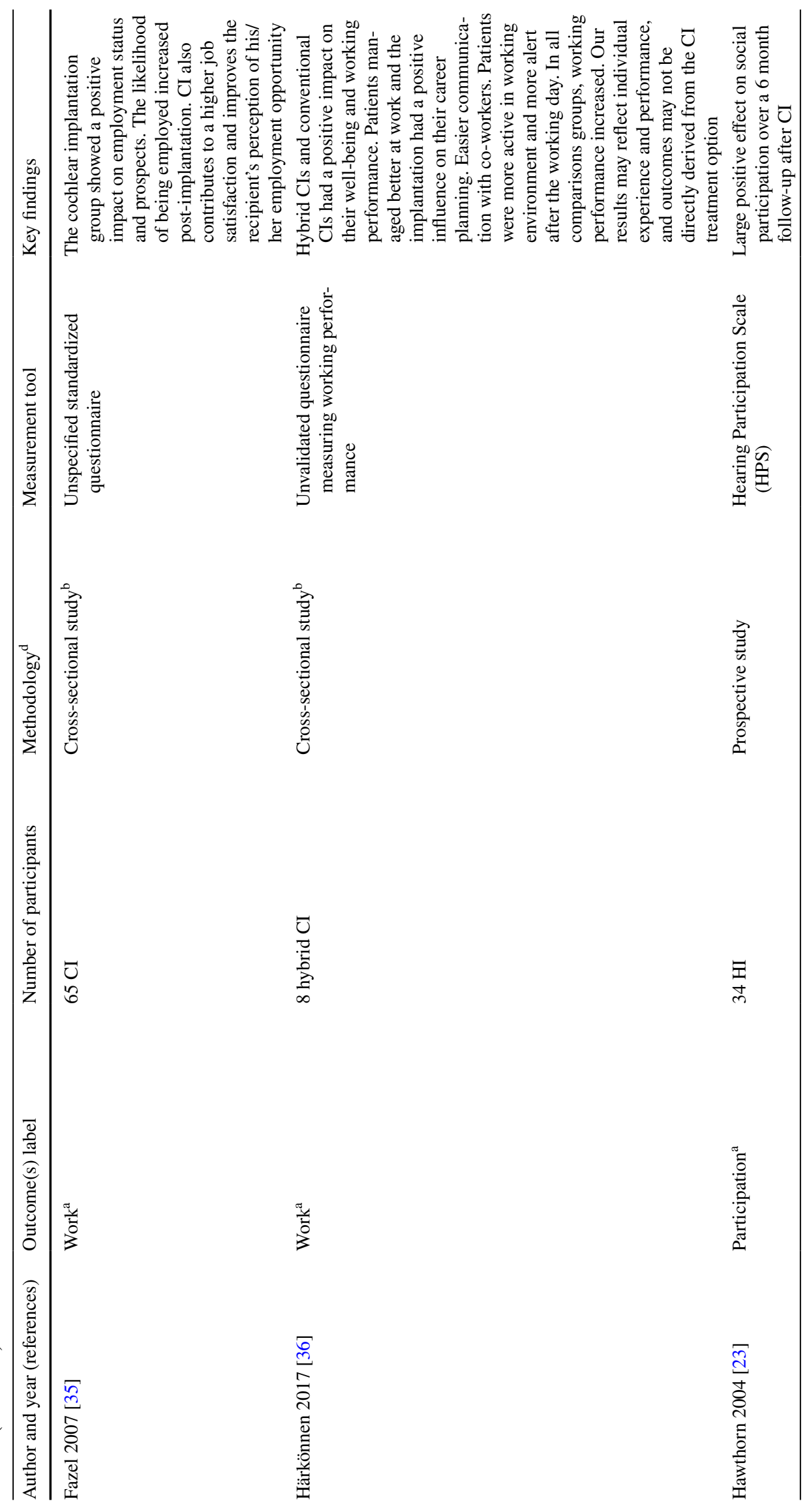


3142

European Archives of Oto-Rhino-Laryngology (2021) 278:3135-3154

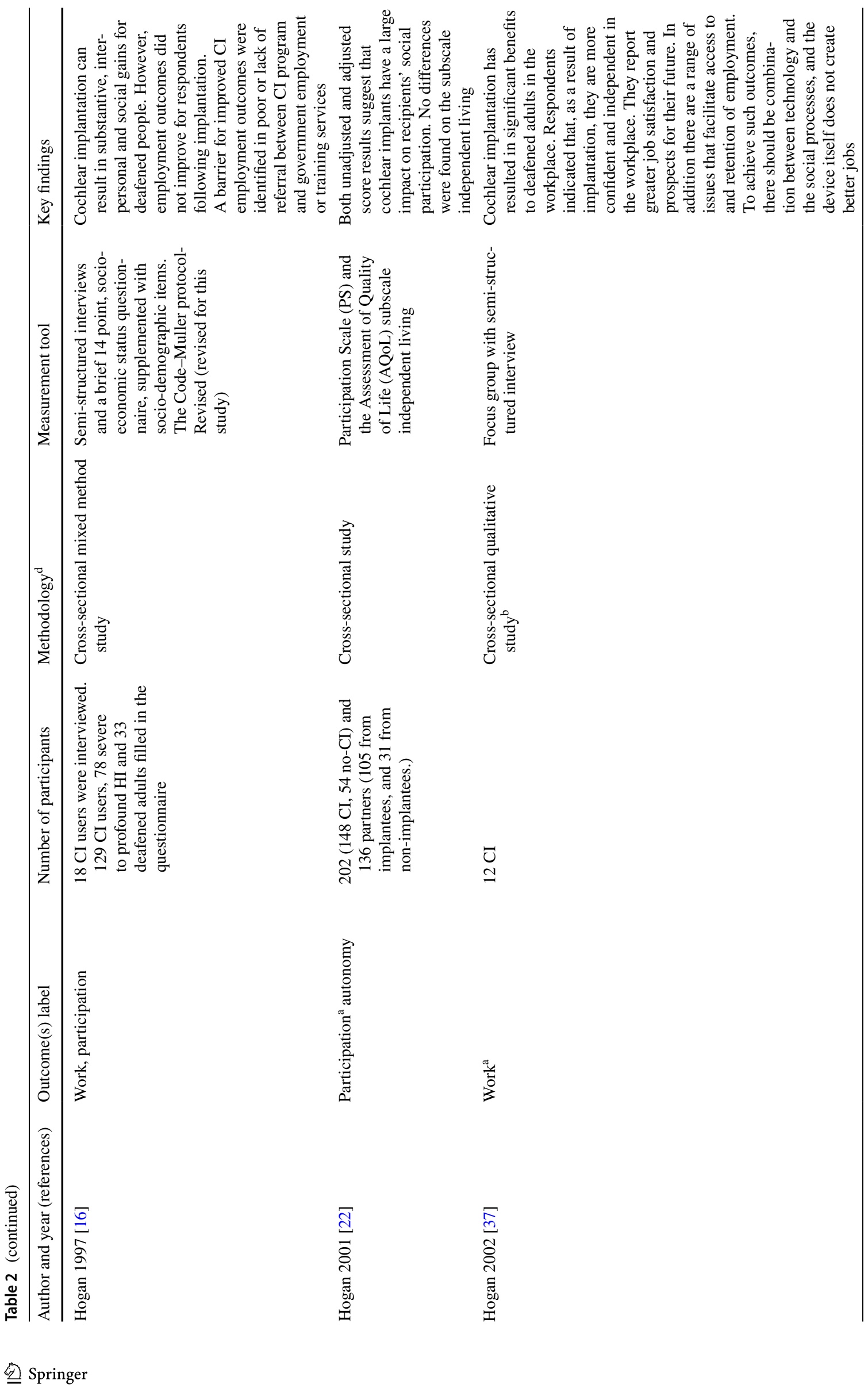




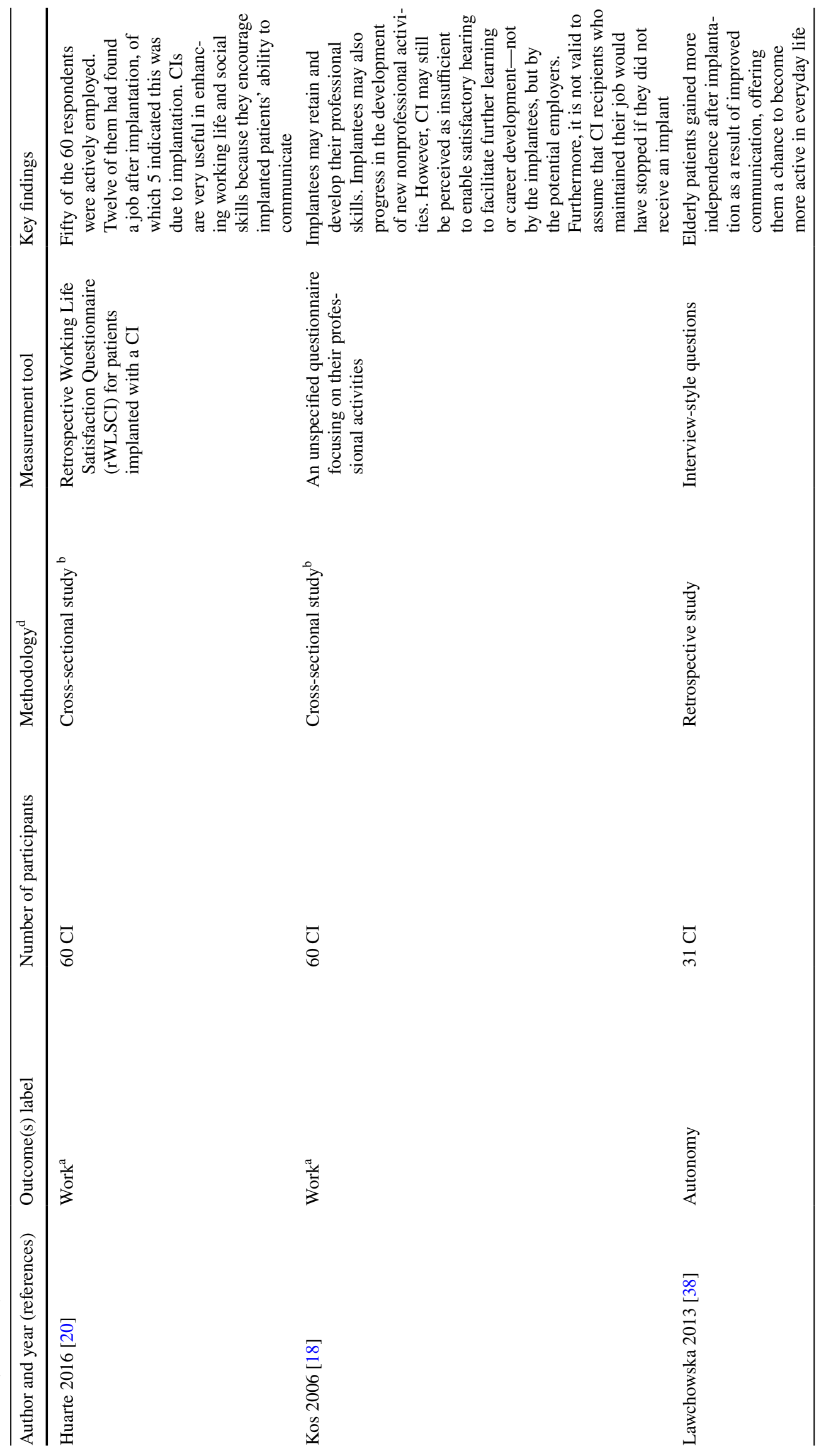




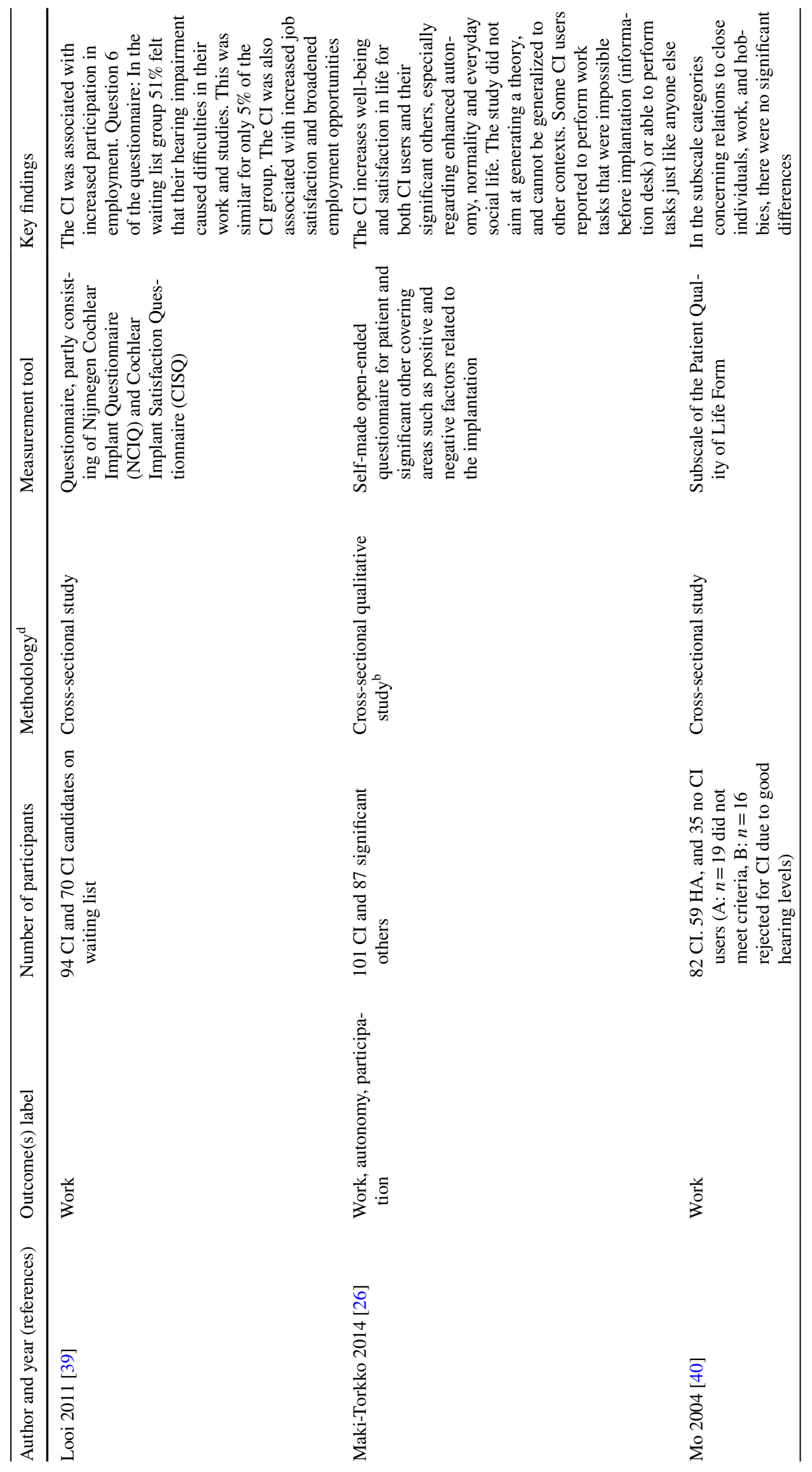




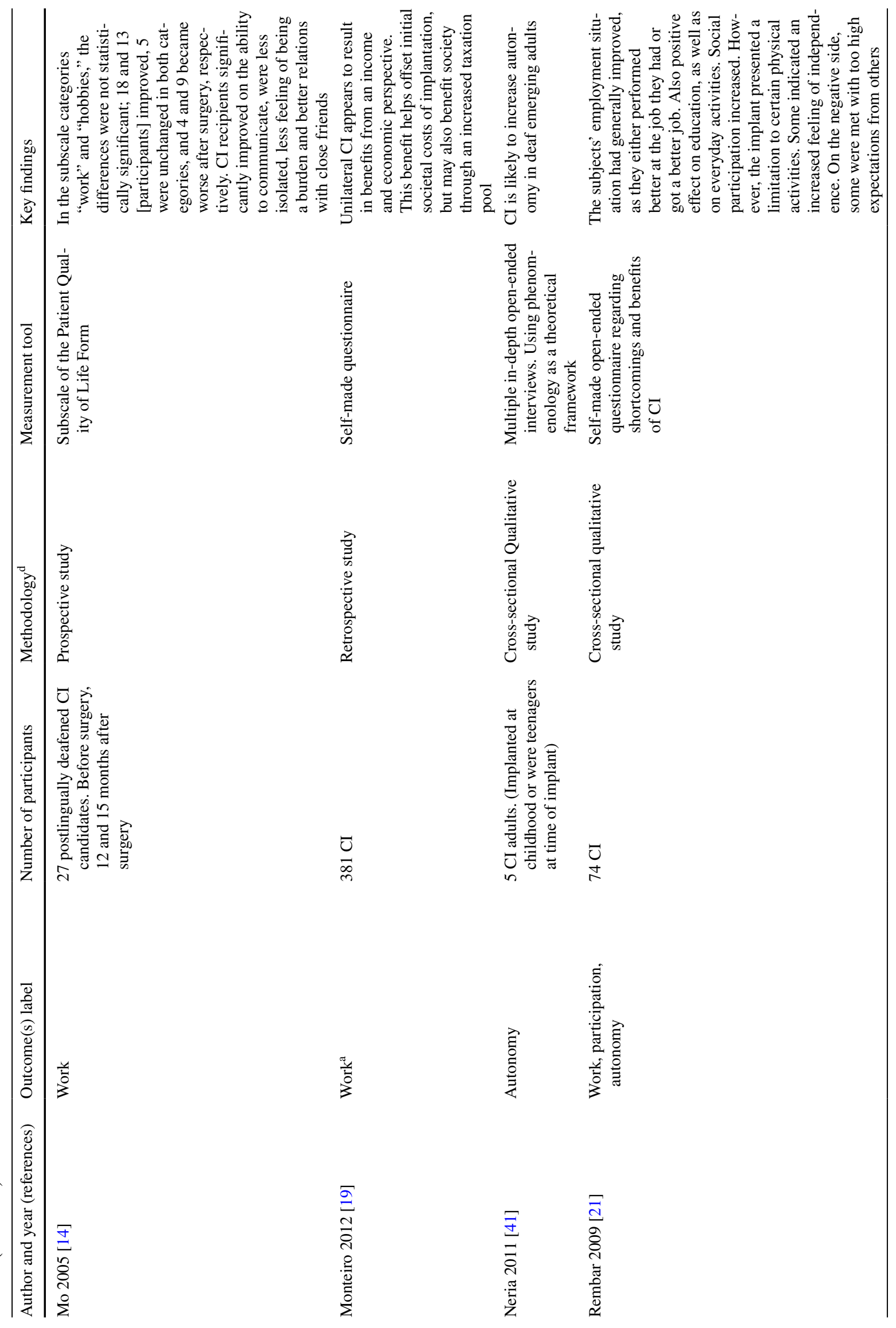




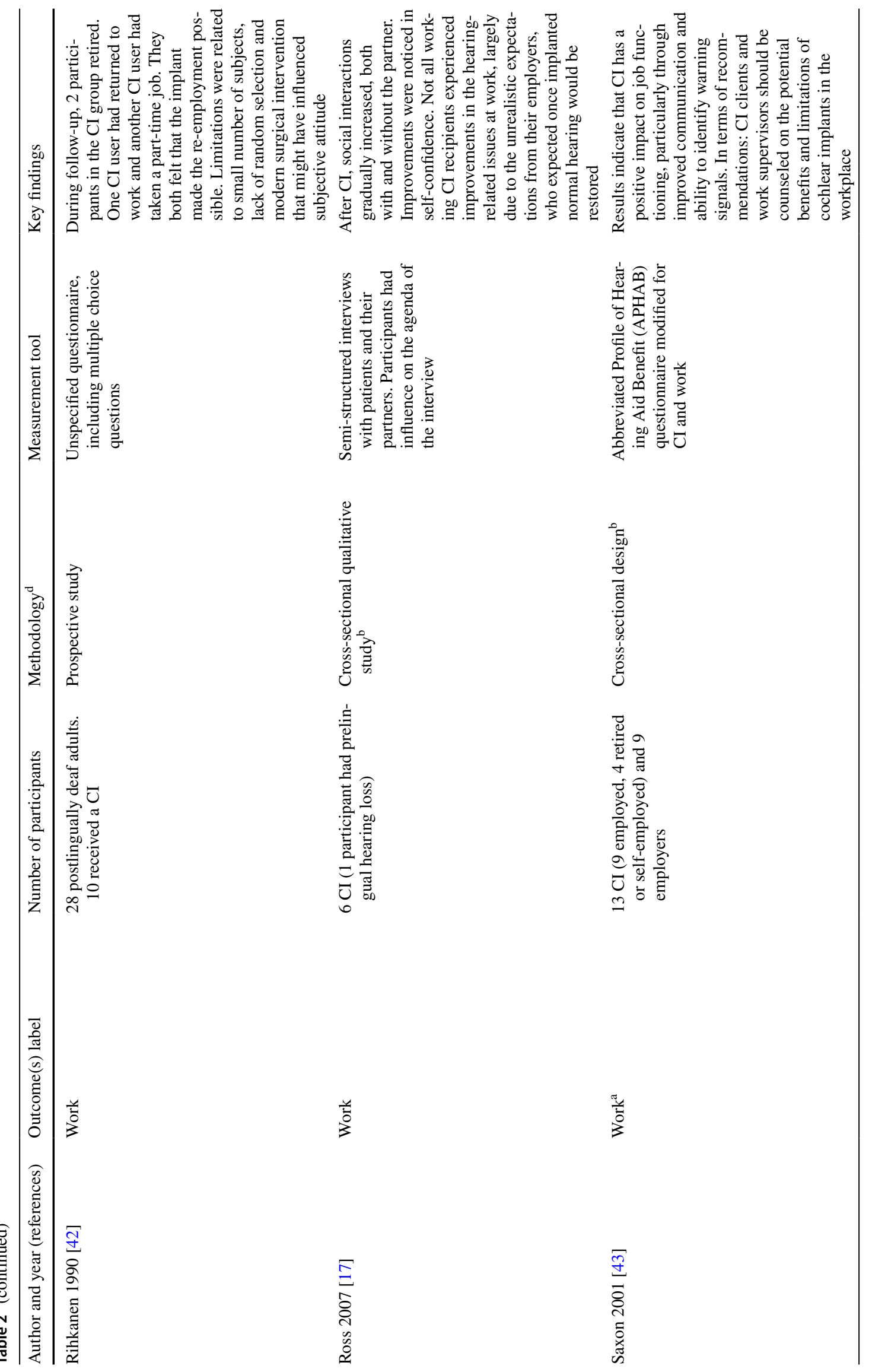




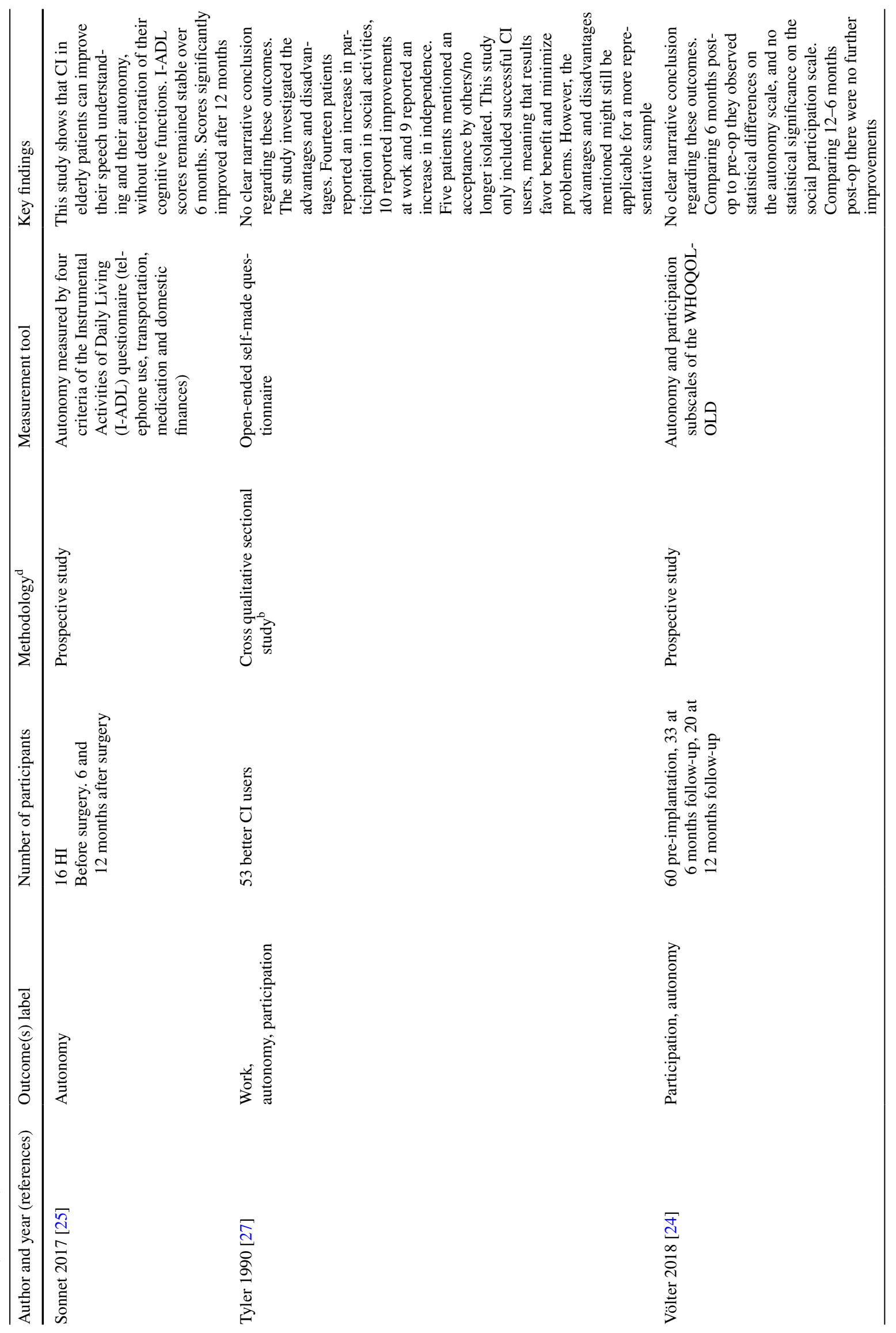




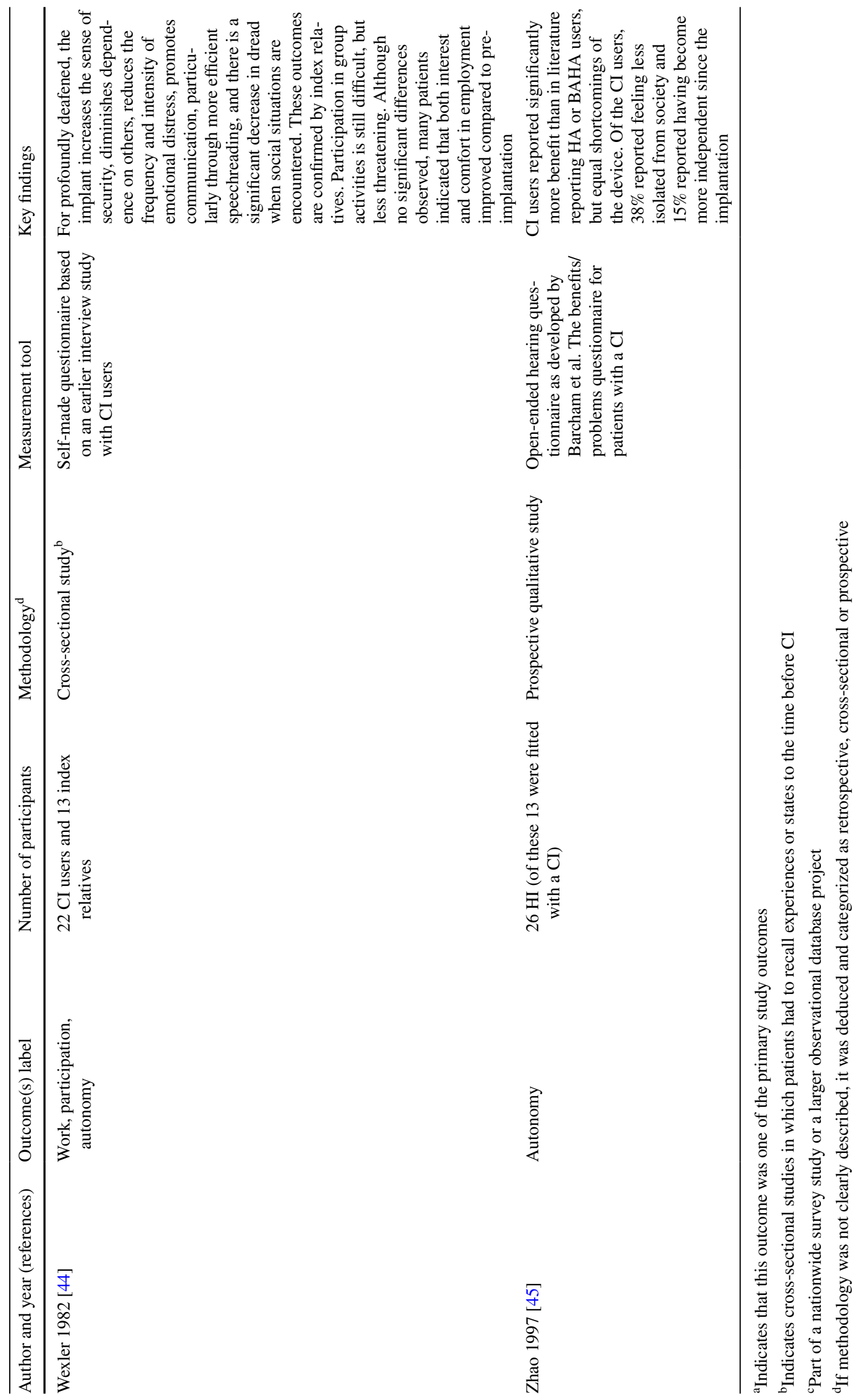


However, the implant rehabilitation program did not include employment support. For the CI recipients who remained or retained at their job experienced an improvement in the way they were treated [16]. The study of Ross et al. 2007, in which they interviewed six CI recipients, identified that not all working $\mathrm{CI}$ recipients experienced an improvement at work, mainly due to their employers, who expected that after implantation the patient's normal hearing would be restored [17]. Finally, the quantitative cross-sectional study of Kos et al. 2007 concluded that although CI users may retain and develop their professional skills, potential employers may still perceive $\mathrm{CI}$ as insufficient to enable satisfactory hearing to facilitate further learning or career development [18].

Monteiro et al. 2012 conducted a retrospective study in which they used data from originally included 637 hearingimpaired patients, $45.3 \%$ of which reported to be employed at the time of diagnosis of hearing loss. Of the 301 employed patients at the time of hearing loss diagnosis (who provided sufficient data), $36.7 \%$ reported to have suffered negative impact on employment as a result of their hearing loss $(20 \%$ lost job; 9.5\% early retirement; $7.2 \%$ long-term disability). At the time of initial assessment for CI, 269 subjects reported to be employed; this resembles a $5 \%$ decrease in employment compared to the employment rates at the time of hearingimpaired diagnosis [19]. Only 381 patients provided sufficient data in the follow-up period post-implantation for analysis. After implantation, $51.1 \%$ of the patients reported to be employed, which was an increase of $10.8 \%$ compared to the initial assessment. $34.2 \%$ of the patients reported a change in their employment after implantation, of which $77.8 \%$ reported a positive change in employment status, compared to $22.2 \%$ who either suffered a negative impact on employment or elected to retire shortly following implantation. Of the subjects who sustained a positive change in employment status following cochlear implantation, 83.8\% felt that this was attributable to being implanted [19]. Huarte et al. 2017 conducted a cross-sectional study in which 60 CI recipients with a mean age of 48 years were included to retrospectively asses to what extent $\mathrm{CI}$ affected their working lives [20]. 83.3\% were actively employed at the time of completing the questionnaire. 12 participants (20\%) indicated to have found employment after implantation, and 5 of those 12 attributed this to receiving the implant. In this study, $41.2 \%$ of the respondents felt a decrease in discrimination at work after cochlear implantation. This might be in line with the findings of scores of cultural challenges presented by Chapman 2017 [15]. Finally, the qualitative cross-sectional study of Rembar et al., who used a self-made open-ended questionnaire (consisting of four questions) regarding shortcomings and benefits of CI, observed the subjects' employment situation had generally improved, as they either performed better at the job they had or got a better job [21]. Similar to the study of Ross et al., some patients reported they were met with too high expectations from others [17].

\section{Participation}

In total, nine studies investigated or identified (social) participation as one of their outcomes. Two of these were prospective quantitative studies. The other seven studies were cross-sectional studies, three used quantitative methods, three used qualitative methods and one used a mixed methods approach. Only three studies explicitly aimed to investigate participation as part of the primary objective, the remaining six were either identified as participation during the research or were used to develop a research tool. Most of the identified studies suggest a positive effect of cochlear implantation on (social) participation. However, the national-based cross-sectional study of Chapman et al. showed surprising results regarding participation [15]. When analyzing all participants, they observed that $\mathrm{CI}$ recipients $(n=254)$ reported to be more limited by their hearing loss and reported to participate statistical significantly less in mainstream organizational activities compared to participants without implantation $(n=547)$. When divided over age groups, similar results were found regarding the participation in mainstream organizations scores in the younger than 26 years group, but there were no significant differences found in the older than 25 years group [15]. However, in the analysis of all participants and the group older than 25 years they reported that $\mathrm{CI}$ recipients were more likely to socialize with hearing friends compared to participants without a CI [15]. The cross-sectional study of Hogan et al. 2001 [22] is the second largest included study after Chapman et al. They included $148 \mathrm{CI}$ recipients and 54 no-CI recipients with no statistical difference between time since onset of deafness between the groups. Hogan et al. used the Participation Scale (PS), which was derived from the Glasgow Health Status Inventory. They observed an overall significant increase of $29 \%$ on PS comparing implantee versus non-implantee [22]. According to the author, this suggests that CI has a large impact on a person's social participation. In the prospective study of Hawthorn et al., they included 34 participants who completed the Hearing and Participation Scale (HPS) before surgery and with a follow-up of 3 and 6 months after surgery. There were significant improvements on the HPS score between baseline and 3 months follow-up and between 3 and 6 months follow-up [23]. The other prospective study of Völter et al. reported scores of the social participation subscale of the generic quality of life tool WHOQOL-OLD [24]. 60 participants provided data prior to implantation, 33 of these were reassessed 6 months after implantation and 20 participants were assessed after 12 months. Even though general QoL improved at 6 months after implantation, they 
did not find statistical significant improvement on the subscale social participation [24].

\section{Autonomy}

Autonomy was measured or identified in ten studies. Three were classified as prospective studies, two quantitative and one qualitative. One study was a retrospective qualitative studies. The remaining six studies were cross-sectional, two quantitative and four qualitative, studies. None of these studies primarily aimed to gain specific insight into the outcomes autonomy or independence, meaning that all ten studies identified autonomy or independence during qualitative investigation, included it as part secondary outcome or it was part of subdomain score. Almost all studies that measured or identified perceptions relating to autonomy or independence suggest benefit after implantation. The quantitative prospective study of Sonnet 2017 was primarily interested in QoL and cognitive function in elderly patients (age: 65-80) [25]. They used the WHOQOL-OLD instrument, but did not report individual subscale scores. However, they also investigated autonomy by using the Instrumental Activities of Daily Living (I-ADL) questionnaire. Autonomy scores were assessed in 16 patients preoperatively and in 14 patients at 6 and 12 months after surgery. At 6 months after surgery, the autonomy scores were stable, with no statistical significant difference. The autonomy scores did improve at 12 months after surgery (mean 0.94 and $p<0.05$ ) [25].

The other quantitative prospective study of Völter et al. 2018 did report the autonomy subscale of WHOQOL-OLD [24]. In this study, 60 patients were included pre-operatively, 33 completed assessment at 6 months follow-up and 20 completed the 12 months follow-up. General quality of life improved at 6 months after implantation, more specifically they also reported a statistical significant improvement WHOQOL-OLD autonomy subscale [24]. Maki et al. 2014 conducted a qualitative cross-sectional study in which they used self-made open-ended questionnaires for CI recipients $(n=101)$ and their significant others (family member or close friends, $n=87$ ). This questionnaire covered areas such as pre-operative expectations and positive and negative factors related to the implantation [26]. They also investigated the perceived life changes and impact of the CI user's significant other. They identified three subcategories: alienation-normality, fear-autonomy, living social life. These were considered to be interrelated and contributing to well-being and life satisfaction [26]. Both the CI users and significant others reported gain in autonomy, as the significant other no longer had to be a social bridge for the patient, reducing stress. CI users reported they could now handle social situations by themselves. The cross-sectional study of Tyler et al., investigated 53 "high performing" CI recipients. They also used a self-made open-ended questionnaire and showed that
9 of 53 patients reported an increase in independence after implantation [27].

\section{Communication, QoL and cognition}

A total of 83 publications investigating QoL, cognition or communication, were included in the literature search; however most were not further analyzed for data extraction because they did not report on outcomes work, participation or autonomy. In these publications, there were some systematic reviews, with overlapping search results with our scoping review, especially regarding QoL and cognition. No systematic reviews were identified regarding the effect of CI on self-perceived communication by the patient. Although the systematic review of Gaylor et al., investigated communication-related outcome, but they maintained a different definition compared to the current review. They defined communication-related outcomes as the evaluation of speech perception (with either open-set sentence or word tests) [28]. The systematic review did conclude that unilateral CI is an effective method for improving speech perception and HRQoL [28].

McRackan et al. conducted two systematic reviews including meta-analysis, both in 2018 [29, 30]. The first review investigated hearing loss or CI-specific quality of life measures and the correlation with speech recognition ability [29]. In the current scoping review, we identified 11 of the 14 studies that were also included by McRackan et al. The difference of three studies is most likely due to differences in inclusion criteria. McRackan et al., concluded that their meta-analysis showed a large positive effect of cochlear implantation on QoL when using CI-specific patientreported outcome measures (PROMs). In addition, the (pooled) correlation between speech recognition scores and hearing—or CI—specific QoL measures were considered negligible.

The other systematic review and meta-analysis by McRackan et al., investigated generic health-related quality of life measures [30]. In this systematic review, 22 publications met criteria for the meta-analysis. However, due to incomplete reporting regarding the statistics, only seven studies were used for meta-analysis. All these seven studies were identified, but not analyzed, in our current scoping review. The authors concluded that the meta-analysis showed a medium positive effect of CI on health-related quality of life. Similar to the earlier mentioned hearing-specific QoL measures, the correlation between speech recognition and generic QoL measures was considered negligible. In both the meta-analyses, generic and hearing/CI-specific QoL, a total of 16 unique studies were analyzed. In our scoping review, we identified a total of 91 studies regarding QoL. This discrepancy is probably caused by the different goals of the review and maintained inclusion and exclusion criteria. 
Furthermore, Crowson et al., conducted a narrative review regarding the evidence of HRQoL and cost-effectiveness of unilateral and bilateral CI in children and adults. They provide a clear overview of design, used QoL measurement instruments and findings of some QoL studies also identified in our scoping review [31].

Claes et al. conducted a systematic review regarding cognitive outcomes [32], mainly focusing on older adults (aged $50+$ ) with bilateral hearing loss. Change in performance on cognitive tests was the primary outcome of interest. Studies using questionnaires were excluded and the included designs had to be longitudinal consisting of at least one pre- and one post-implantation measurement. Six studies met these criteria. All these studies were also identified in our literature search regarding cognition $(n=10)$. Five of these studies reported improvement in cognition after cochlear implantation [32]. However, in the discussion the authors stated that the studies had several risks of bias and were considered inconclusive. Claes et al., proposed the use of cognitive assessment tools that are adequately adapted to hearing-impaired individuals including a description of the modifications. To control for learning effects, they suggested using alternative forms. According to the authors, it was advised to perform more appropriate statistical analysis regarding the characteristics of the sample, descriptive values and outcomes.

\section{Discussion}

In this scoping review, we aimed to explore the extent, measurements and types of studies that are available in scientific literature regarding unilateral cochlear implantation in adults with postlingual bilateral hearing loss on societal outcomes: work, autonomy, participation. In a total of 27 published studies, these outcomes were measured or reported 20, 10 and 9 times, respectively. Some studies included more than one of the above-mentioned outcome measures, hence the total number of measured outcomes (no) is larger than the total number of included studies $(n)$. Insight is provided on the papers regarding autonomy, participation and work $(n=27)$. Most of the studies had a cross-sectional design $(n=18)$, some were retrospective studies $(n=3)$, while some were prospective $(n=6)$. The outcomes work, autonomy and participation were the primary objectives in 11 of the 27 studies. To prevent for missing papers that might have measured or identified work, autonomy and participation, the literature search was extended with the terms "quality of life", "cognition" and "communication" which resulted in approximately six additional studies that would otherwise be excluded in title-abstract screening.

Most of the studies in this scoping review suggest a positive influence of CI on the outcomes work, autonomy and participation. However, some of the studies identified negative consequence of CI, mainly in terms of expectations by others. It was also indicated that it is important that CI recipients notify their communication partners as well as their employers and colleagues about the personal benefits and limitations that accompanies their CI use.

Based on this literature review, we would like to discuss several findings: (1) Generalizability and study year: It is known that qualitative study designs make generalizability difficult. Since some of the included publications in this review describe qualitative studies, conducted for exploratory purposes and to get more insight into the experiences of CI recipients, outcomes are less generalizable. Generalizability of study results to current practice is also impeded by the fact that some studies were rather old. Five of the included studies were over 20 years old. The participants in these studies had access to previous CI systems (including single channel CI) which may have provided incomparable results to the use of modern CI systems. A second issue with older studies is the assessment of a different study population in terms severity of hearing loss. This is the result of the fact that criteria for CI have broadened [46, 47]. Patients receiving a $\mathrm{CI}$ today frequently suffer from progressive hearing loss and have more residual hearing than patients who received a CI in the past. If a patient has no or very limited residual hearing, then there is more room for improvement which may make the older CIs look more effective than the newer ones. On the other hand, nowadays in general there is more residual hearing present pre-implantation and the time of auditive deprivation is shorter leading to better performance [46]. At this point, it is hard to determine whether these factors have resulted in an over- or underestimation of effects, but it is worth noting that the result from these older studies may differ from the more recent situation. (2) Many factors influence outcomes: When assessing or comparing studies regarding societal outcomes, it should be noted that more variables besides the CI device and surgery influence the results [35, 37]. Therefore, it is important to consider the entire CI procedure including aftercare and training services, mainly because there might be variation in this rehabilitation/aftercare program per country/center that could influence results on outcomes as work [16], autonomy, participation and probably QoL and daily living. (3) Methodology: Some limitations were reported regarding the methodology. A frequently reported limitation was a small sample size, followed by recall bias for retrospective- and cross-sectional studies. As shown in Table 1, no randomized controlled trials (RCT) were included. A possible explanation for this is that it is challenging to conduct an RCT with $\mathrm{CI}$ without ethical concerns [23]. There is no appropriate alternative treatment (that can serve as control group) for $\mathrm{CI}$ in patients with these levels of hearing loss [23, 40]. Comparison with another control group may not be valid because of variability 
in influential psychophysical and social characteristics, so they are not prognostically equivalent. Furthermore, many included studies used measurement tools that were either not specified or validated, which may create a risk for bias. Partially as a result of these limitations, studies commonly reported recommendation for larger-scale, prospectively longitudinal studies.

There are also some limitations in this review. Albeit the thorough and deliberate process of creating the search strategy, using a relatively large set of search terms, it might be possible that some synonymous terms were overlooked in our search. Publications that used slightly different terms were not found or identified during screening and might not have been included in this scoping review. However, if we missed any studies regarding these outcomes it is likely it does not drastically influence our findings and general direction of interpretation. Furthermore, the aim of scoping reviews is to give a broad, rather than in-depth, insight related to a particular research question. So, in this study we have been inclusive toward all study designs, including (retrospective, cross-sectional and prospective studies) various assessment tools and qualitative studies. In our review, we cannot determine if the included studies and their direction of results were the consequence of publication bias or nonreporting of negative results, which might be caused by the risk that significant results are more likely to be published or presented. In addition to including various types of studies, we included only studies that defined, either qualitatively coded or measured, specific outcomes. We identified the often implicit overlap and interrelation between definitions of our outcomes of interest (i.e., participation, QoL, autonomy) and specific measurement scales. It is therefore sometimes difficult to unravel the differences in definitions and what is actually being measured. The often lacking consensus around the definition of social participation and the consequence for analysis and policy was partially the rationale for Levasseur et al. to provide an inventory and content analysis of these varying definitions [48]. In our scoping review, this resulted in maintaining a strict terminology (defined it as participation autonomy or independence) and including studies in this review according to these terms. For example; the NCIQ is the disease-specific HRQoL questionnaire, which contains a domain regarding social interactions. This subscale was not included for data extraction in this literature study, for it was not specifically defined as participation, though questions or subscales regarding social interaction might be similar to those investigating participation. On the other hand, the study of Hawthorn and Hogan adjusted the Glasgow Health Status Inventory to create the shortened (Hearing and) Participation Scale (HPS and PS). These studies were included for it was explicitly stated to measure participation according to their definition. Furthermore, some general terms like quality of life consists of multiple domains, and an increase in quality of life does not entail that all the subdomains are improved, for example regarding the IPQLF which was included for further analysis because of the subscale 'work' [14, 40]. They did not show a statistical significant improvement in work, but the overall quality of life scale did show improvement in the CI group compared to one of the two no-CI groups. In line with this reasoning, when research is conducted, both generic and specific measures or subscales can be valuable to use for investigation. This mainly depends on the eventual purposes of the generated knowledge and how it will be used. For example, more generic normativebased instruments could be used in decision regarding resource allocation and comparison between different disease areas $[49,50]$. Subscales and disease-specific tools might provide specific information in comparing relatively similar groups or for identifying specific targets for improvement. This should also preferably be driven by what is valuable to the patient from the concept of value-based health care.

In this scoping review, we provided an overview of the current body and level of evidence investigating the effect of cochlear implantation on the societal-related outcomes work, autonomy and participation. It can be concluded that there is a relatively small body of evidence that measured these societal outcomes, specifically there is a relatively small amount of prospective studies. On the other hand, a relatively large number of studies have been published (or recently reviewed) investigating QoL, cognition and communication.

Current literature review also underlines the interrelation between specific outcomes (i.e., autonomy, independence, participation) and subdomains of generic measures such as health-related quality of life measures. The included studies in this review investigated these outcomes separately. Making these outcomes explicit can be important for specifically guiding innovation and policy, to be able to provide better care by determining what is valuable for patients and eventually improving a patients' quality of life. The value of these detailed explicit research outcomes depends on the decisionmaker and end users of the research results.

In conclusion, based on the included studies in this scoping review, CI seems to have a beneficial effect on societal outcomes in terms of participation, autonomy and work. In times of increased scarcity of health-care budgets, this type of evidence is needed for policy and decision-makers. Today, the amount of robust scientific evidence regarding the effect of CI on the societal outcome measures is scarce. To overcome this omission, additional research on the societal outcomes of cochlear implantation in postlingually deafened adults is needed. Large prospective studies, using validated tools should overcome the most prevalent limitations (small sample size, non-validated tools and retrospective design) of 
the included studies in this review. These limitations greatly lowered the strength of the evidence of the included studies.

Author contributions WJH, EAMM and HGBN conceived the ideas. NK and HGBN collected the data. HGBN and NMK analysed that data with additional discussions with WJH and EAMM. EAMM, WJH, HGBN and NMK led the writing.

Funding This was an investigator-initiated research. No funding was received to assist with the preparation of this manuscript.

Data availability Data are published or available upon request.

\section{Compliance with ethical standards}

Conflict of interest The authors have no conflicts of interest to declare that are relevant to the content of this article.

Open Access This article is licensed under a Creative Commons Attribution 4.0 International License, which permits use, sharing, adaptation, distribution and reproduction in any medium or format, as long as you give appropriate credit to the original author(s) and the source, provide a link to the Creative Commons licence, and indicate if changes were made. The images or other third party material in this article are included in the article's Creative Commons licence, unless indicated otherwise in a credit line to the material. If material is not included in the article's Creative Commons licence and your intended use is not permitted by statutory regulation or exceeds the permitted use, you will need to obtain permission directly from the copyright holder. To view a copy of this licence, visit http://creativecommons.org/licenses/by/4.0/.

\section{References}

1. Olusanya BO, Neumann KJ, Saunders JE (2014) The global burden of disabling hearing impairment: a call to action. Bull World Health Organ 92(5):367-373. https://doi.org/10.2471/ blt.13.128728

2. Kramer SE, Kapteyn TS, Houtgast T (2006) Occupational performance: comparing normally-hearing and hearing-impaired employees using the Amsterdam Checklist for Hearing and Work. Int J Audiol 45(9):503-512. https://doi.org/10.1080/1499202060 0754583

3. Nachtegaal J, Smit JH, Smits C, Bezemer PD, van Beek JH, Festen JM, Kramer SE (2009) The association between hearing status and psychosocial health before the age of 70 years: results from an internet-based national survey on hearing. Ear Hear 30(3):302312. https://doi.org/10.1097/AUD.0b013e31819c6e01

4. Lin FR, Yaffe K, Xia J, Xue QL, Harris TB, Purchase-Helzner E, Satterfield S, Ayonayon HN, Ferrucci L, Simonsick EM (2013) Hearing loss and cognitive decline in older adults. JAMA Intern Med 173(4):293-299. https://doi.org/10.1001/jamaintern med.2013.1868

5. Strawbridge WJ, Wallhagen MI, Shema SJ, Kaplan GA (2000) Negative consequences of hearing impairment in old age: a longitudinal analysis. Gerontologist 40(3):320-326. https://doi. org/10.1093/geront/40.3.320

6. Cunningham LL, Tucci DL (2017) Hearing loss in adults. N Engl J Med 377(25):2465-2473
7. Olusanya BO, Davis AC, Hoffman HJ (2019) Hearing loss grades and the International classification of functioning, disability and health. Bull World Health Organ 97(10):725-728. https://doi. org/10.2471/BLT.19.230367

8. Bond M, Mealing S, Anderson R, Elston J, Weiner G, Taylor RS, Hoyle M, Liu Z, Price A, Stein K (2009) The effectiveness and cost-effectiveness of cochlear implants for severe to profound deafness in children and adults: a systematic review and economic model. Health Technol Assess 13(44):1-330. https:// doi.org/10.3310/hta13440

9. Dutch National Institute for Public Health and the Environment (RIVM) (2018) De Volksgezondheid Toekomst Verkenning 2018. https://www.vtv2018.nl/aandoeningen. Accessed Apr 2020

10. Peters MD, Godfrey CM, McInerney P, Soares CB, Khalil H, Parker D (2015) The Joanna Briggs Institute reviewers' manual 2015: methodology for JBI scoping reviews (2015)

11. Tricco AC, Lillie E, Zarin W, O'Brien KK, Colquhoun H, Levac D, Moher D, Peters MDJ, Horsley T, Weeks L, Hempel S, Akl EA, Chang C, McGowan J, Stewart L, Hartling L, Aldcroft A, Wilson MG, Garritty C, Lewin S, Godfrey CM, Macdonald MT, Langlois EV, Soares-Weiser K, Moriarty J, Clifford T, Tuncalp O, Straus SE (2018) PRISMA extension for scoping reviews (PRISMAScR): checklist and explanation. Ann Intern Med 169(7):467-473. https://doi.org/10.7326/m18-0850

12. Straatman LV, Huinck WJ, Langereis MC, Snik AF, Mulder JJ (2014) Cochlear implantation in late-implanted prelingually deafened adults: changes in quality of life. Otol Neurotol 35(2):253259. https://doi.org/10.1097/MAO.0b013e3182a4758e

13. Ouzzani M, Hammady H, Fedorowicz Z, Elmagarmid A (2016) Rayyan-a web and mobile app for systematic reviews. Syst Rev 5(1):210. https://doi.org/10.1186/s13643-016-0384-4

14. Mo B, Lindbaek M, Harris S (2005) Cochlear implants and quality of life: a prospective study. Ear Hear 26(2):186-194. https://doi.org/10.1097/00003446-200504000-00006

15. Chapman M, Dammeyer J (2017) The relationship between cochlear implants and deaf identity. Am Ann Deaf 162(4):319_ 332. https://doi.org/10.1353/aad.2017.0030

16. Hogan A (1997) Implant outcomes: towards a mixed methodology for evaluating the efficacy of adult cochlear implant programmes. Disabil Rehabil 19(6):235-243

17. Ross L, Lyon P (2007) Escaping a silent world: profound hearing loss, cochlear implants and household interaction. Int J Consum Stud 31(4):357-362. https://doi.org/10.111 1/j.1470-6431.2006.00561.x

18. Kos M, Degive C, Boex C, Guyot J (2007) Professional occupation after cochlear implantation. J Laryngol Otol 121(3):215-218

19. Monteiro E, Shipp D, Chen J, Nedzelski J, Lin V (2012) Cochlear implantation: a personal and societal economic perspective examining the effects of cochlear implantation on personal income. J Otolaryngol Head Neck Surg 41(Suppl 1):S43-S48

20. Huarte A, Martínez-López M, Manrique-Huarte R, Erviti S, Calavia D, Alonso C, Manrique M (2017) Work activity in patients treated with cochlear implants. Acta Otorrinolaringol (English Edition) 68(2):92-97

21. Rembar S, Lind O, Arnesen H, Helvik AS (2009) Effects of cochlear implants: a qualitative study. Cochlear Implants Int 10(4):179-197

22. Hogan A, Hawthorne G, Kethel L, Giles E, White K, Stewart M, Plath B, Code C (2001) Health-related quality-of-life outcomes from adult cochlear implantation: a cross-sectional survey. Cochlear Implants Int 2(2):115-128. https://doi.org/10.1179/ cim.2001.2.2.115

23. Hawthorne G, Hogan A, Giles E, Stewart M, Kethel L, White K, Plaith B, Pedley K, Rushbrooke E, Taylor A (2004) Evaluating the health-related quality of life effects of cochlear implants: 
a prospective study of an adult cochlear implant program. Int J Audiol 43(4):183-192. https://doi.org/10.1080/149920204000500 26

24. Volter C, Gotze L, Dazert S, Falkenstein M, Thomas JP (2018) Can cochlear implantation improve neurocognition in the aging population? Clin Interv Aging 13:701-712. https://doi. org/10.2147/cia.S160517

25. Sonnet MH, Montaut-Verient B, Niemier JY, Hoen M, Ribeyre L, Parietti-Winkler C (2017) Cognitive abilities and quality of life after cochlear implantation in the elderly. Otol Neurotol 38(8):e296-e301. https://doi.org/10.1097/mao.000000000000150 3

26. Maki-Torkko EM, Vestergren S, Harder H, Lyxell B (2015) From isolation and dependence to autonomy - expectations before and experiences after cochlear implantation in adult cochlear implant users and their significant others. Disabil Rehabil 37(6):541-547. https://doi.org/10.3109/09638288.2014.935490

27. Tyler RS, Kelsay D (1990) Advantages and disadvantages reported by some of the better cochlear-implant patients. Am J Otol 11(4):282-289

28. Gaylor JM, Raman G, Chung M, Lee J, Rao M, Lau J, Poe DS (2013) Cochlear implantation in adults: a systematic review and meta-analysis. JAMA Otolaryngol Head Neck Surg 139(3):265272. https://doi.org/10.1001/jamaoto.2013.1744

29. McRackan TR, Bauschard M, Hatch JL, Franko-Tobin E, Droghini HR, Nguyen SA, Dubno JR (2018) Meta-analysis of quality-of-life improvement after cochlear implantation and associations with speech recognition abilities. Laryngoscope 128(4):982-990. https ://doi.org/10.1002/lary.26738

30. McRackan TR, Bauschard M, Hatch JL, Franko-Tobin E, Droghini HR, Velozo CA, Nguyen SA, Dubno JR (2018) Meta-analysis of cochlear implantation outcomes evaluated with general healthrelated patient-reported outcome measures. Otol Neurotol 39(1):29-36. https://doi.org/10.1097/mao.0000000000001620

31. Crowson MG, Semenov YR, Tucci DL, Niparko JK (2017) Quality of life and cost-effectiveness of cochlear implants: a narrative review. Audiol Neurootol 22(4-5):236-258. https://doi. org/10.1159/000481767

32. Claes AJ, Van de Heyning P, Gilles A, Van Rompaey V, Mertens G (2018) Cognitive outcomes after cochlear implantation in older adults: a systematic review. Cochlear Implants Int 19(5):239-254. https://doi.org/10.1080/14670100.2018.1484328

33. Clinkard D, Barbic S, Amoodi H, Shipp D, Lin V (2015) The economic and societal benefits of adult cochlear implant implantation: a pilot exploratory study. Cochlear Implants Int 16(4):181-185

34. Czerniejewska-Wolska H, Kałos M, Sekula A, Piszczatowski B, Rutkowska J, Rogowski M, Zadrożniak M, Szymański M, Klatka J, Durko M, Pietruszewska W, Gawłowska MB, Kuśmierczyk J, Kruk-Krzemień A, Wiskirska-Woźnica B (2015) Quality of life and hearing after cochlear implant placement in patients over 60 years of age. Otolaryngol Pol 69(4):34-39. https://doi. org/10.5604/00306657.1163575

35. Fazel MZ, Gray RF (2007) Patient employment status and satisfaction following cochlear implantation. Cochlear Implants Int $8(2): 87-91$

36. Härkönen K, Kivekäs I, Kotti V, Sivonen V, Vasama J-P (2017) Hybrid cochlear implantation: quality of life, quality of hearing, and working performance compared to patients with conventional unilateral or bilateral cochlear implantation. Eur Arch Otorhinolaryngol 274(10):3599-3604

37. Hogan A, Stewart M, Giles E (2002) It's a whole new ball game! Employment experiences of people with a cochlear implant. Cochlear Implants Int 3(1):54-67

38. Lachowska M, Pastuszka A, Glinka P, Niemczyk K (2013) Is cochlear implantation a good treatment method for profoundly deafened elderly? Clin Interv Aging 8:1339-1346. https://doi. org/10.2147/cia.S50698

39. Looi V, Mackenzie M, Bird P, Lawrenson R (2011) Quality-of-life outcomes for adult cochlear implant recipients in New Zealand. N Z Med J 124(1340):21-34

40. Mo B, Harris S, Lindbaek M (2004) Cochlear implants and health status: a comparison with other hearing-impaired patients. Ann Otol Rhinol Laryngol 113(11):914-921. https://doi. org/10.1177/000348940411301111

41. Neria CM (2011) Emerging adults with cochlear implants: their experiences and lifeworlds. Chapman University, Orange

42. Rihkanen H (1990) Subjective benefit of communication aids evaluated by postlingually deaf adults. Br J Audiol 24(3):161-166. https://doi.org/10.3109/03005369009076551

43. Saxon JP, Holmes AE, Spitznagel RJ (2001) Impact of a cochlear implant on job functioning. J Rehabil 67(3):49

44. Wexler M, Miller LW, Berliner KI, Crary WG (1982) Psychological effects of cochlear implant: patient and "index relative" perceptions. Ann Otol Rhinol Laryngol Suppl 91(2 Pt 3):59-61

45. Zhao F, Stephens SD, Sim SW, Meredith R (1997) The use of qualitative questionnaires in patients having and being considered for cochlear implants. Clin Otolaryngol Allied Sci 22(3):254-259. https://doi.org/10.1046/j.1365-2273.1997.00036.x

46. Huinck WJ, Mylanus EAM, Snik AFM (2019) Expanding unilateral cochlear implantation criteria for adults with bilateral acquired severe sensorineural hearing loss. Eur Arch Otorhinolaryngol 276(5):1313-1320. https://doi.org/10.1007/s0040 5-019-05358-z

47. Naples JG, Ruckenstein MJ (2020) Cochlear Implant. Otolaryngol Clin N Am 53(1):87-102. https://doi.org/10.1016/j. otc.2019.09.004

48. Levasseur M, Richard L, Gauvin L, Raymond E (2010) Inventory and analysis of definitions of social participation found in the aging literature: proposed taxonomy of social activities. Soc Sci Med 71(12):2141-2149. https://doi.org/10.1016/j.socsc imed.2010.09.041

49. Wells GA, Russell AS, Haraoui B, Bissonnette R, Ware CF (2011) Validity of quality of life measurement tools-from generic to disease-specific. J Rheumatol Suppl 88:2-6. https://doi.org/10.3899/ jrheum.110906

50. Hunink MGM, Weinstein MC, Wittenberg E, Drummond MF, Pliskin JS, Wong JB, Glasziou PP (2014) Decision making in health and medicine: integrating evidence and values, 2 nd edn. Cambridge University Press, Cambridge. https://doi.org/10.1017/ CBO9781139506779

Publisher's Note Springer Nature remains neutral with regard to jurisdictional claims in published maps and institutional affiliations. 